\title{
ERRATUM
}

Horst Huck

\section{The non-integer cyclovoltammetric electron-exchange numbers of reversible redox reactions of adsorbates}

Published online: 17 March 2004

(C) Springer-Verlag 2004

\section{J Solid State Electrochem (2004) 8:89-93}

The beginning of Eq. (27) should be read as $i_{\text {true }}$ instead of ni $i_{\text {true }}$.

$$
i_{\text {true }}=\frac{n}{n_{\text {app }}^{\prime}} i_{\text {app }}=\frac{n}{n_{\text {app }}^{\prime}} C_{\mathrm{ps}, \mathrm{app}} v
$$

